\title{
Object-centered Process Modeling: Principles to Model Data-intensive Systems
}

\author{
Rui Henriques ${ }^{1}$ and António Rito Silva ${ }^{1}$ \\ Center for Organization and Engineering (CODE) - INESC-ID \\ Instituto Superior Técnico (IST-UTL), Lisboa, Portugal \\ rui.henriques@inov.pt, rito.silva@inov.pt
}

\begin{abstract}
New modeling approaches appeared in the last decade based on the premise that process structures in data-intensive landscapes are pushed by data-driven events. However, since emergent approaches, as artifact-centric, data-driven, product-based and document-based modeling, cover reduced subsets of all data-related needs, they have a limited practical impact [13]. This work structures the set of requirements to model responsive data-intensive systems, studies the emergent objectcentered approaches to retrieve a set of principles and, finally, defines a solution direction, centered in expressive object models and in model transformations, for the support of the introduced principles.
\end{abstract}

Key words: process modeling, data-intensive system, object-orientation

Topics: Concepts: data- and event-driven BPM; Design-time CEP: modeling notations and methods for event-driven BPM. LongPaper category.

\section{Introduction}

The increasingly uncertain, dynamic and data-intensive landscape where some systems operate triggers challenges to process models evolution, either when processes need to be modeled from scratch or, as this work focuses, to organically adapt through local improvements. Since data-intensive systems highly depend on how their passive participants - system entities subjected to transformation - to prescribe its elements coordination, their evolution is pushed by changes at the data level. Exemplifying, a health-care system that relies on the state and mediation of patients, exams, reports and historicals to deliver a diagnosis, evolves by changing the way these participants are constrained through process models in order to abstract and prescribe the new desired operation [29].

In traditional approaches, the modelind of processes is independent from the system data, historically hidden behind applications [23], disabling synergies between informational and functional views required for data-intensive scenarios.

Process models can create an environment for the evolution of data-intensive systems if they foster: integration by prescribing the relationships among system elements while bridging functional, informational, organizational, technological and contextual views [33], and adaptability and agility by promoting flexible and data-centered models with changes performed in a timely manner [19]. 
Motivation. Barriers for the evolution of data-intensive process models are pointed in [19][13]. Their resolution is particularly important for scientific workflow systems [1], manufacturing systems [22][18], government systems [7] or insurance systems [31]. Common problems of traditional approaches include the context-isolated enactment of activities causing data-access challenges and a loss of the process global view, the absence of criteria for the activities granularity and the rigidity required to specify networks of activities when loosely-coupled, dynamic and data-based constraints foster models flexibility and expressivity.

Results from research [6][18] support the fact that a system modeling integrating the data and process perspectives reveals opportunities that disrupt traditional modeling discipline. The natural outcome orientation of many administrative and operational processes [32] turns the progress of single process instances not directly dependent on the execution of activities but reactive on data changes [13]. Contrasting to traditional approaches that force the system modeling into monolithic processes, objects seem promising to model data-based processes as they capture the system operation as a collection of intertwined loosely-coupled life-cycles running at different speeds [29], coping with different levels of granularity [13] and providing a natural basis to derive key performance indicators [6], to become the ground of process users vocabulary [6], to define access levels [9] and to model systems' constraints in usable ways [15].

Since data-intensive processes rely on the premise that relations between the passive participants' components implicitly define sub-process dependencies [13], new ways of dynamically support processes' evolution can be exploited.

Contribution. This work proposes an analysis of the potentialities of emergent object-centered approaches to develop a solution basis of an approach where retrieved lessons coexist to foster the evolution of data-intensive systems.

Although research exist in the scope of process modeling centered on objects [13] and on process evolution [24], since existing approaches were developed to face small and specific sets of concerns [13], their practical applicability coverage and impact is limited [13]. This seems unaccountable in the contemporary era where, for instance, AI systems, several enterprises and many of their subsystems are truly data-intensive systems. This observation fosters the need to re-look to them from scratch in order to understand how potentialities can be combined.

This work systematizes the object-centered universe and it serves as a metaguider for principles integration on tacit and data-intensive process modeling.

Structure. This work is divided into four logical sections. First, Conceptual Foundations, provides a structured context for the universe of discourse. Second, Related Work, identifies a set of requirements based on the limitations of traditional modeling approaches, and studies how emergent approaches answer them. Third, Solution Basis, presents a set of principles that restrict the solution space, derives an initial skeleton for their coexistence and presents some of the taken concretion and implementation directions. Finally, Concluding Remarks, presents the resultant theorems and lines of thought for future research. 


\section{Conceptual Foundation}

The Systemic Context. Inserted in the context of increasing data-intensive landscapes, this work adopts the process perspective to introduce new postulates on the modeling of system elements coordination that fosters evolution. Concepts are introduced below to structure the object-centered modeling.

Def.1 A system is a tuple $\langle R, C, E, G\rangle$, where $R$ is the structure, set of relationships among a composition of system elements $C$ and external elements $E$, that satisfies a purpose $G$ grounded on exchanges with its environment [8].

The system composition, $C$, is a set of subsystems or, from an elementary perspective, a set of participants $P$. Participants can either be passive $\left(P_{P} \subset P\right)$ if subjected to transformation by a set of system actions, or active or agents $\left(P_{A} \subset P\right)$ if performing actions aimed at changing passive participants [5].

Def. 2 System evolution is the process of increasing the system responsiveness to its environment by continually optimizing the efficiency to pursue its purpose under changing conditions. It depends on its ability to behave as an integrated, adaptable and agile system, i.e., to timely improve its structure $\left(R \rightarrow R^{\prime}\right)$ when internal, external or purposeful changes occur $\left(\{C, E, G\} \rightarrow\{C, E, G\}^{\prime}\right)$.

Functional decomposition of a system defines hierarchies of abstractions needed for the modeling of systems operation [33]. Activities, units of work, are its nodes. In open $(E \neq \emptyset)$ and dynamic or multi-state systems, a system act or an event (implying a system action) produces a change to the system state. System activities coherently and consistently relate system acts.

Def.3 A system process, $<A_{\wp}, P_{\wp}, G_{\wp}, R_{\wp}>$, structures a set of system activities $\left(A_{\wp} \subseteq A\right)$ performed in a constrained manner $\left(R_{\wp} \subseteq R\right)$ based on the coordination of a set of system participants $\left(P_{\wp} \subseteq P\right)$ to realize a set of system goals $\left(G_{\wp} \subseteq G\right)$. A process model is a model for system processes, an abstraction $m\left(A_{\wp}, P_{\wp}, G_{\wp}, R_{\wp}\right)$, which describes and prescribes the operation of an object system by its interacting systems based on its functional composition.

The Role of Data. Different data taxonomies for process modeling can be found in [34][25]. Weske [33] depicts the role of data within processes according to data visibility, interaction, transfer and support to routing logic. Aalst [30] distinguishes two main types of data: case and non-case. Case data is the data used by system applications to support activities. Non-case data can be divided into support data, if it affects the process routing logic, and management data, if it is produced by the process execution environment (e.g. audit trails). Muehlen [34] does the same distinction under a different analysis.

In fact, this work simplifies this taxonomy into data generated and consumed by processes [34]. The reason behind this simplification - the increasingly blurry boundary between data exposed for process routing decisions and pure application data - lead us, finally, to the notion of data-intensive system.

In data-intensive systems, the data consumed and generated by some of system elements is related with the production of other system elements [34].

Def.4 A data-intensive system is a system with a structure $R$ that relates its elements $C$ based on data mediation and transformation. Thus, its operation 
is constrained by the passive participants' state and relations or, more broadly, by the way the system productions to the environment realize the system goals.

For instance, automotive industrial systems rely on the entanglement of data components, the passive participants, to deliver a physical production. Claimprocessing systems use claimer's information, regulatory and financial reviews and claim state to audit and deliver a decision.

Def.5 A process within a data-intensive landscape is referred as dataintensive process. Scientific research has been focusing on two main types of data-intensive processes: $i$ ) processes driven by the state of passive participants [6][31] and ii) collaborative and tacit processes that use passive participants as record objects to capture the system operation [26].

Research on data-intensive vertents has been adopting different terms as documents, products and artifacts, here all generalized and captured as objects, either simple or compound (encapsulating a set of related objects). Objects, either representing logical or physical elements, can be seen as building blocks that bridge the functional and informational perspectives [6].

Def. 6 A system object represents any relevant state-based system element, either a simple participant or a composition of system participants. Its state is defined by the object content and it is modified during its life-cycle as the result of an invocation of a set of activities that act upon its data-attributes.

Informational decomposition of a system defines hierarchies of object models.

Modeling Orientation. Process modeling approaches can be divided according to their main focus of modeling: activity-flow, agent-coordination or data-needs focus lead, respectively, to activity-centered, agent-centered or objectcentered languages. For instance, agent-centered modeling is the natural choice for processes with strict distribution of responsibilities owned by specialized agents, since activities precedences are implicitly derived from agent-interaction constraints [17]. This work also distinguishes multi-paradigm approaches where process models have not a clear orientation [5], and hybrid approaches where different approaches co-exist exposing different views for different users.

Since objects are generically used to model simple and compound structures of system participants, the dependencies among activities in object-centered approaches is derived from constraints on these participants state and relations.

Def.7-1 An object-centered process model is a process model that uses the knowledge of the participants composition $P_{\wp}$ to derive the system structure under modeling $R_{\wp}$. Modeling of participants must be expressive, so changes at the system data models dynamically affect the system process models.

If we recover the system definition, we detect four main perspectives: functional, informational, instrumental and contextual, or, respectively, the activitybased, object-based, agent-based and goal-based views. All these models are integrated by a process model, the governance model, which constrains their interaction to capture and prescribe the operation of a target system.

Fig.1 and Fig.2 depict, respectively, an abstract data-intensive system and the different system modeling views structure. 


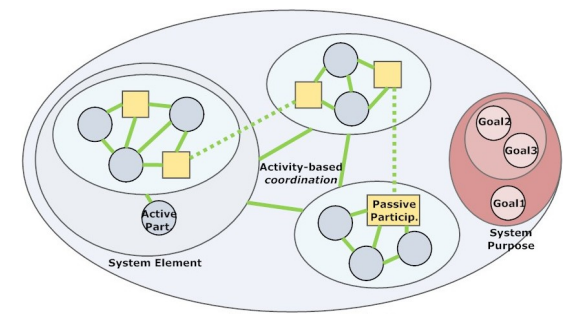

Fig. 1. Abstract data-intensive system

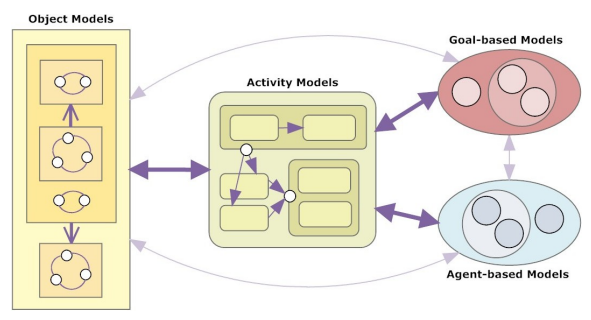

Fig. 2. Abstract process model

\section{Related Work}

In this section the research problem is reduced to five requirements and emergent approaches are evaluated according to their ability to answer them.

Research Problem. The pushing of passive participants to the processes background as a result of an historical hidden of data behind service and application layers is explained in [33][34]. Seven reasons are pointed in [23]. Nevertheless, our work aims to develop an environment for the integrated management of system data and system activities since their independence in data-intensive landscapes blocks benefits obtained from their coupled evolution.

IBM's Global Financing company, a system specialized in financing assets with disciplined regional variations, is partially depicted in Fig.3. The process modeling layer was based on a typical activity-centered approach. A synthesized description of the traditional approaches limitations in supporting the evolution of data-intensive process models is presented in Table 1.

This study led this analysis to a point where the initial problem was breakdown into five pieces. Table 2 structures the five requirements triggered by the limitations of traditional approaches when modeling data-intensive processes.

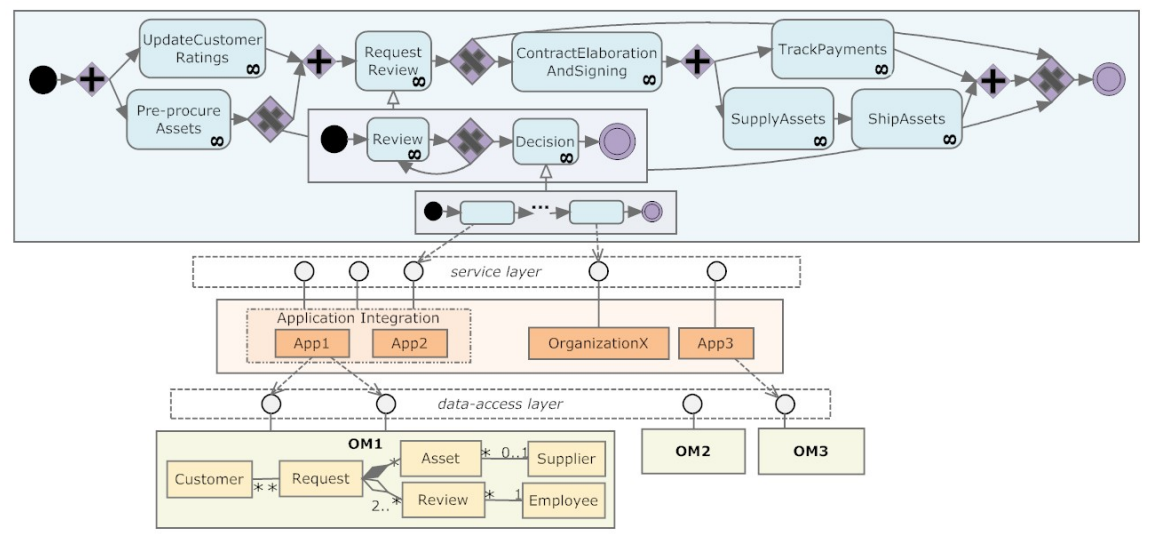

Fig. 3. Traditional Process Modeling Landscape 


\begin{tabular}{|c|c|c|}
\hline Problems & $G F$ Challenges (Fig.3 upgrades) & $\begin{array}{l}\text { Area } \\
\text { Concern }\end{array}$ \\
\hline $\begin{array}{l}\text { Process data redundantly created with ap- } \\
\text { plication data poses consistency problems. } \\
\text { Isolated execution of activities cause lost } \\
\text { of process global view and data-access } \\
\text { specification must be explicit for every ac- } \\
\text { tivity and is not maintained among them, } \\
\text { leading to non-usable models. } \\
\text { There is not support for an integrated ac- } \\
\text { cess to old or non-related process data; }\end{array}$ & $\begin{array}{l}\text { Reviews or contract negotiations become af- } \\
\text { fected by the state of assets procurement (if } \\
\text { running in parallel) or other request's re- } \\
\text { views, their progress depends on customer's } \\
\text { past requests' or similar customers' or re- } \\
\text { quests' information, and their contextual } \\
\text { data continues accessible without the need } \\
\text { to specify all attributes as input parameters } \\
\text { for each activity; }\end{array}$ & Data \\
\hline $\begin{array}{l}\text { Activities have to be related in a net } \\
\text { of ordering dependencies, turning difficult } \\
\text { a spontaneously repetition of process in- } \\
\text { stances, their stoppage and caught up at } \\
\text { a later point in time and a dynamic reac- } \\
\text { tion on data conditions; }\end{array}$ & $\begin{array}{l}\text { Negotiation becomes reactively available on } \\
\text { a condition over reviews related-data sat- } \\
\text { isfaction, and not depending on executing } \\
\text { reviews progress. Assets and reviews are in- } \\
\text { stantiated dynamically based, respectively, } \\
\text { on request and customer's data; }\end{array}$ & $\begin{array}{l}\text { Data-state } \\
\text { Reaction }\end{array}$ \\
\hline $\begin{array}{l}\text { Process instances (from the same or dif- } \\
\text { ferent process specifications) are executed } \\
\text { in isolation to each other, hampering } \\
\text { the support for expressive communication } \\
\text { patterns among processes }\end{array}$ & $\begin{array}{l}\text { Decoupling of assets procurement from re- } \\
\text { view or negotiation process segments, al- } \\
\text { though synchronized. Aggregation of re- } \\
\text { lated segments, as reviews or assets supply- } \\
\text { ing and shipping, for similar requests; }\end{array}$ & $\begin{array}{l}\text { Data-based } \\
\text { Synchron. }\end{array}$ \\
\hline $\begin{array}{l}\text { Service layers turn impossible the defini- } \\
\text { tion of criteria for the processes granular- } \\
\text { ity since client application activities may } \\
\text { reside at different granular levels; }\end{array}$ & $\begin{array}{l}\text { Activities for accessing and changing cus- } \\
\text { tomer or request attributes (e.g. customer } \\
\text { address) must be available, and their com- } \\
\text { position must follow concrete criteria; }\end{array}$ & $\begin{array}{l}\text { Data-based } \\
\text { Granularity }\end{array}$ \\
\hline $\begin{array}{l}\text { Since data-centered and activity-centered } \\
\text { models are separated by an application } \\
\text { layer, modeling of data objects is roughly } \\
\text { done at the process modeling level. }\end{array}$ & $\begin{array}{l}\text { A request becomes handled by multiple cus- } \\
\text { tomers (the process modeling environment } \\
\text { detects the change of an association multi- } \\
\text { plicity on an underlying data model). }\end{array}$ & $\begin{array}{l}\text { Data } \\
\text { Modeling }\end{array}$ \\
\hline
\end{tabular}

Table 1. Problems of Traditional Modeling Approaches in Data-Intensive Landscapes

Introductory remarks for the understanding of data-awareness requirements can be found in [13][14][20]. Table 2 reviews and structures them under a taxonomy oriented to incremental steps for process models' evolution.

Def. 8 An object-centered system is, thus, a data-intensive system with a structure $R$ that satisfies the introduced requirements, i.e., a system where its passive participants are visible to every system agent, dynamically affect activities progress and composition, and are adequately accessed and expressively captured at the process modeling level.

State-of-the-Art Analysis. Six mature object-centered approaches were evaluated according to their ability to answer to the introduced five requirements. Their selection was based on the practical maturity, data-orientation and novelty of aspects. Table 3 groups these approaches and clarifies their focus.

Results were collapsed in Table 4 . We say that an approach answers a requirement when satisfies almost of its clauses, partially answers a requirement when satisfies at least one of its clauses, and not answers a requirement if does not approach it. A brief analysis done in Table 5 supports the presented results.

Data-based multiple instantiation [12], batch-orientation [3], objects and activities connection through procedural links [10], data-based clustering for objects definition [16] or the attachment of operational semantics within objects [6] are some other interesting directions on this field of knowledge.

Discussion reveals that each approach answers in different ways to the introduced requirements. Neither approach satisfies all of them, which may justify 


\begin{tabular}{|c|c|}
\hline $\begin{array}{l}\text { Data } \\
\text { Access }\end{array}$ & $\begin{array}{l}\text { Process and application data must be coherently and consistently integrated, meaning } \\
\text { that system's process and object models must be bridged and evolve in a coupled way } \\
\text { according to a well-defined set of relations. } \\
\text { Process models must avoid data-context tunneling (causing the loss of a broader view } \\
\text { on the process) when executing isolated or groups of activities, and additionally must } \\
\text { expressively hold data-access contexts from single to multiple activities [31]. Data- } \\
\text { scope specification must additionally be usable, seizing benefits of data models ex- } \\
\text { pressivity (e.g. include references to complex data-objects or to sets of objects). } \\
\text { Authorized users must access data at any time regardless of the process status [31][14]; }\end{array}$ \\
\hline $\begin{array}{l}\text { Data-state } \\
\text { Reaction }\end{array}$ & $\begin{array}{l}\text { Processes must dynamically react on object state constraints, i.e., it is optional to } \\
\text { define of network of activities' precedences. Since activities are related to objects, } \\
\text { they must dynamically adapt their behavior (e.g. availability) based on objects' state } \\
\text { (horizontal dynamic granularity) [13] and provide a natural method to deduce omissive } \\
\text { path localization, minimizing sequentiality and, thus, fostering process flexibility; }\end{array}$ \\
\hline $\begin{array}{l}\text { Data-based } \\
\text { Synchro. }\end{array}$ & $\begin{array}{l}\text { Processes must use object models constructors to express advanced patterns of syn- } \\
\text { chronization, including the definition of: i) multiple related instances aggregation or } \\
\text { vertical aggregation to reduce execution effort (e.g. group related requests) [3], ii) } \\
\text { asynchronous points of coordination to minimize processes coupling (e.g. synchronize } \\
\text { the progress of a set of instances responsible for the assets procurement with their } \\
\text { related request) [13], and iii) expressive transition's rule-sets; }\end{array}$ \\
\hline $\begin{array}{l}\text { Data-based } \\
\text { Granularity }\end{array}$ & $\begin{array}{l}\text { Atomicity and composition of activities must be based on the underlying process data } \\
\text { [13] to, respectively, safeguard the availability of fine-grained activities and a criteria } \\
\text { for an hierarchy with levels of modeling abstractions; }\end{array}$ \\
\hline $\begin{array}{l}\text { Data } \\
\text { Modeling }\end{array}$ & $\begin{array}{l}\text { There must be possible to model and adapt object models at the process modeling } \\
\text { level [13]. Evolution of processes is, thus, fostered by the previous requirements, which } \\
\text { assure that execution constraints are dynamically derived from the dependencies of } \\
\text { object models in a usable manner, with this one, which enables modeling flexibility. }\end{array}$ \\
\hline
\end{tabular}

Table 2. Data-related Requirements for Object-centered Approaches

\begin{tabular}{|l|l|l|l|}
\hline \multicolumn{2}{|c|}{ Approach } & Process constraints driven from... & Belief \\
\hline $\begin{array}{l}\text { Document-based } \\
\text { Modeling }\end{array}$ & {$[21][2]$} & $\begin{array}{l}\text { documents dependencies (either } \\
\text { internal and external) }\end{array}$ & $\begin{array}{l}\text { documents shape and track all the op- } \\
\text { erations of data-intensive systems }\end{array}$ \\
\hline $\begin{array}{l}\text { Artifact-centric } \\
\text { Modeling }\end{array}$ & {$[11][4]$} & $\begin{array}{l}\text { artifacts' state and life-cycle syn- } \\
\text { chronization (restricting activity } \\
\text { models invocation) }\end{array}$ & $\begin{array}{l}\text { artifacts' information models and syn- } \\
\text { chronized states fosters data access } \\
\text { and processes modularity }\end{array}$ \\
\hline $\begin{array}{l}\text { Product-based } \\
\text { Modeling }\end{array}$ & {$[22][32]$} & $\begin{array}{l}\text { production components dependen- } \\
\text { cies and quality criteria affecting } \\
\text { activity ordering }\end{array}$ & $\begin{array}{l}\text { models for the systems production con- } \\
\text { tain the needed information to affect } \\
\text { the process flow }\end{array}$ \\
\hline $\begin{array}{l}\text { Case Handling } \\
\text { Cata-driven }\end{array}$ & {$[31][28]$} & $\begin{array}{l}\text { data-objects labeled associations } \\
\text { and activities precedences }\end{array}$ & $\begin{array}{l}\text { activities of data-intensive cases can be } \\
\text { captured and grouped as form-based } \\
\text { operations over simple data-objects }\end{array}$ \\
\hline Proclets & {$[27][29][18]$} & $\begin{array}{l}\text { object models' internal transitions } \\
\text { and relationship types }\end{array}$ & $\begin{array}{l}\text { dependencies among passive compo- } \\
\text { nents completely prescribe and sup- } \\
\text { port evolution of complex processes }\end{array}$ \\
\hline data-container objects' life-cycles & $\begin{array}{l}\text { modeling centered on processes com- } \\
\text { munication, instead of ordering em- } \\
\text { phasis, fosters modeling expressivity }\end{array}$ \\
\hline
\end{tabular}

Table 3. Chosen Object-centered Approaches

\begin{tabular}{|c|c|c|c|c|c|}
\hline Approach & $\begin{array}{l}\text { 1.Data } \\
\text { Access }\end{array}$ & $\begin{array}{l}\text { 2.Data-state } \\
\text { Reaction }\end{array}$ & $\begin{array}{l}\text { 3.Data-based } \\
\text { Synchronization }\end{array}$ & $\begin{array}{l}\text { 4.Data-based } \\
\text { Granularity }\end{array}$ & $\begin{array}{l}\text { 5.Data } \\
\text { Modeling }\end{array}$ \\
\hline Document-based Modeling & $+/-$ & + & $+/-$ & - & $+/-$ \\
\hline Artifact-centric Modeling & - & + & $+/-$ & $+/-$ & $+/-$ \\
\hline Product-based Modeling & - & - & + & $+/-$ & $+/-$ \\
\hline Data-driven Coordination & - & - & - & $-/-$ & $+/-$ \\
\hline Case Handling & + & + & + & - & $+/-$ \\
\hline Proclets & - & - & + & - \\
\hline
\end{tabular}

Table 4. Approaches Evaluation [subtitles: + answers; +/- partially answers; - not answers] 


\begin{tabular}{|c|c|}
\hline $\begin{array}{l}\text { Document-based } \\
\text { Modeling }\end{array}$ & $\begin{array}{l}\text { It fosters simplicity by modeling constraints recurring to data-dependencies (2), } \\
\text { guides enactement (3), supports authorized data-access using knowledge-bases (1) } \\
\text { and captures ad-hoc forms of collaboration. However, it limits data modeling to } \\
\text { plain structures (4,5), does not support advanced relations among documents (3), } \\
\text { and instances are defined statically (3); }\end{array}$ \\
\hline $\begin{array}{l}\text { Artifact-centric } \\
\text { Modeling }\end{array}$ & $\begin{array}{l}\text { It is oriented to business needs and execution constraints are automatically driven } \\
\text { from artifacts modeling }(2,5) \text {. However, activity data-access is limited to the related } \\
\text { artifact (1), life-cycles synchronization only support few patterns (3) and, finally, } \\
\text { composition of artifacts is not possible (4); }\end{array}$ \\
\hline $\begin{array}{l}\text { Product-based } \\
\text { Modeling }\end{array}$ & $\begin{array}{l}\text { It is good for process models that periodically require a clean-sheet, uses qual- } \\
\text { ity attributes for dynamic path choice (3). However, data-access is restricted to } \\
\text { operations' input components, there must exist an explicit precedence network of } \\
\text { operations (2), and applicability relies on the ability to specify productions using } \\
\text { composition relationships that can be assembled into a single product }(3,4,5) \text {; }\end{array}$ \\
\hline $\begin{array}{l}\text { Data-driven } \\
\text { Coordination }\end{array}$ & $\begin{array}{l}\text { It is indicated for large and numerous concurrently executing processes. It adds } \\
\text { advanced communication patterns, as the definition of synchronization points among } \\
\text { instances belonging to the same or different process type (3), based on objects } \\
\text { relationship types, and allows for complex structures specification that can guide } \\
\text { functional decomposition (5). However it disregards simplicity, data content that } \\
\text { leads to data reaction and access problems }(1,2) \text {, and atomicity of activities (4); }\end{array}$ \\
\hline Case Handling & $\begin{array}{l}\text { It is unique in providing a global view of the process to its users, data-access is } \\
\text { expressive and users can surpass the activities by accessing data for which they } \\
\text { have access levels (1). It allows for horizontal aggregation }(2) \text { and, since it is fully } \\
\text { state-based, it is easy to conceptualize. However, processes hierarchies and data } \\
\text { object-oriented patterns for synchronization purposes are poorly exploited }(3,4,5) \text {; }\end{array}$ \\
\hline Proclets & $\begin{array}{l}\text { It promotes a shift from control to communication emphasis, where processes inter- } \\
\text { act according to an agreed level of reliability, security, closure and formality (3). It } \\
\text { supports multiple messages-exchange patterns and batch-oriented tasks, thus, en- } \\
\text { abling vertical dynamic aggregation of proclets instances (3). Although proclets are } \\
\text { decoupled process fragments, composition is not supported (4) and each fragment } \\
\text { can still be considered an activity-centered model, thus, suffering from same data- } \\
\text { access and data-state reaction limitations }(1,2,5) \text {. }\end{array}$ \\
\hline
\end{tabular}

Table 5. Brief Review of Emergent Approaches' [subtitles: (x) reference to requirement x]

their limited real-case applications coverage and impact. However, lessons can be used to retrieve principles to derive a more mature modeling approach.

\section{Solution Basis}

This section uses the understanding of how emergent approaches answer data requirements to retrieve principles and to define a structure for their coexistence.

Event-orientation. A process is here captured as a set of state-based and synchronized entities - objects, activities and goals. Exemplifying, a transition between states of an entity $A$ can trigger an event for another transition occurrence in an entity $B$ if $B$ has some sort of dependency with $A$.

Two axioms must be introduced. First, process state is a function of time and of its activity, object, and goal models. Second, synchronization among entities is defined through event-driven state transitions recurring to rule-set models.

Object models and activity models in the modeling landscape of data-intensive systems are integrated by a process model (the governance model) that establishes relationships and constrains their interaction through rule-set models.

Note that the notion of system applications that frequently intertwined data and process models are in data-intensive landscapes pushed back and here seen as workflow systems' additions to implement non-trivial system rules. 
Def.7-2 An object-centered process model, $<O M, A M, G M, R M>$, is a model derived from a set of state-based object (or participant) models $O M$, activity models $A M$ and goal models $G M$. These governed models are synchronized through rule-set models $R M$ that constraint the availability to invoke activities based on state restrictions or concessions. It can generically be defined as a pair $<N, E>$ where $N=N_{O M} \cup N_{A M} \cup N_{G M} \cup N_{R M}$, and $E \subseteq N \times N$.

Principles. The solution space constraints that support the satisfaction of the introduced requirements are synthesized in Table 6 . Note that since, execution constraints for data-intensive processes mainly derive from objects' state and relations, object models adaptation becomes the great source to evolve processes.

\begin{tabular}{|c|c|}
\hline $\begin{array}{l}\text { Data } \\
\text { Access }\end{array}$ & $\begin{array}{l}\text { First, all system data is captured (tacit and non-tacit platforms are modeled and } \\
\text { their trace used to feed objects), standardized (by using the proposed data modeling } \\
\text { notation) and accessible (not hidden behind applications). } \\
\text { Second, activity models prescribe objects' data access by specifying labeled associa- } \\
\text { tions, both imperative and declarative, at any granular level of activities and of objects. } \\
\text { Third, related running activities are presented together using forms. Forms fields } \\
\text { change dynamically since aggregate activity-related attributes that can be alternately } \\
\text { submitted and may turn new attributes available. } \\
\text { Fourth, there is a default criteria for the automatic definition of the activities' data } \\
\text { scope based on the object models. An activity has not only access to its related ob- } \\
\text { ject or attribute but may access related/internal/super objects and attributes if these } \\
\text { associations declare public visibility. } \\
\text { Fifth, authorization is separated from distribution using an object-based structure to } \\
\text { manage agents' privilege access levels. }\end{array}$ \\
\hline $\begin{array}{l}\text { Data-state } \\
\text { Reaction }\end{array}$ & $\begin{array}{l}\text { First, the object-centered models' interplay assures that activities react on objects } \\
\text { state in a traceable manner. Even the completion, failure or cancellation behaviour } \\
\text { of an activity is, by omission (although editable), retrieved from its associated object } \\
\text { specification. } \\
\text { Second, it is possible to specify dependencies of different types (e.g. start-to-start) } \\
\text { among data-attributes or any granular level of objects of different types, which gener- } \\
\text { ates expressive dependencies on the functional level and fosters an usable paralleliza- } \\
\text { tion of attributed-based activities and the ability of process models to evolve through } \\
\text { object models adaptation. }\end{array}$ \\
\hline $\begin{array}{l}\text { Data-based } \\
\text { Synchro. }\end{array}$ & $\begin{array}{l}\text { First, object state transitions may depend on conditions over the state of the related } \\
\text { object instances and also affect their markings. Communication among objects, always } \\
\text { mediated by a third object, is derived from object models to process models and it } \\
\text { enables the definition of asynchronous points of synchronization between processes. } \\
\text { Second, the skeleton for the rule-set models is automatically generated on the basis of } \\
\text { their input and output states and of expressive constructors. } \\
\text { Third, rule-set models placed in objects' state transitions can comprise advanced for- } \\
\text { mulas based on aggregation constructors, data-scope settings, time conditions and } \\
\text { executable code additions. }\end{array}$ \\
\hline $\begin{array}{l}\text { Data-based } \\
\text { Granularity }\end{array}$ & $\begin{array}{l}\text { First, each compound activity is a composition of fine-grained activities and for each } \\
\text { data-field exists an activity that triggers system acts to access and modify its content. } \\
\text { Second, object model's relations of encapsulation constitute a criterion to derive the } \\
\text { processes' composition, enabling zoom operations through different operational levels. }\end{array}$ \\
\hline $\begin{array}{l}\text { Data } \\
\text { Modeling }\end{array}$ & $\begin{array}{l}\text { Definition and continuously adaptation of data-intensive system is possible through dy- } \\
\text { namical creation, edition and removal of objects at the process modeling level. Sound- } \\
\text { ness and migration coherency of the affected object-centered instances is assured. }\end{array}$ \\
\hline
\end{tabular}

Table 6. Principles for the FIVE Requirements

Contribution Reviewed. A recently enriched data-centric direction [20] supports most of these principles, although still neglects composition and advanced synchronization patterns. [13] stream of research retrieves a relevant subset of the introduced principles, although does not provide an approach for their support. 
Object-centered investigation besides presenting a basis for all principles integration, is unique in presenting a direction for an approach that: $i$ ) fully derives and adapts process models from enriched data models ([20] still requires the manual definition of activities for the manipulation of system participants), ii) defines advanced behavior based on formal rules, iii) uses objects data-visibility to formulate new soundness criteria, and $i v$ ) exploits object-oriented inheritance and encapsulation patterns for an expressive derivation of processes.

The Process of Modeling Data-intensive Processes. The modeling of the target process models begins with the objects' specification by enriching the system data models with synchronized life-cycles and data dependencies. Ruleset models are used to specify advanced behaviour. Activity models, partially derived from object models, specify the functional aspects and the data-scope. Process models are dynamically derived from the previously defined models.

Object-centered language constructors, soundness criteria and other relevant aspects will be present in future publications. However its main modeling steps can be synthesized by the following algorithm:

1. (Manual) Definition of a data model for the target system using UML;

2. (Automatic) Generation of the object models skeleton;

3. (Manual) Edition of object models to capture the system semantics;

4. (Automatic) Test of object models' soundness. Generation of activity models;

5. (Manual) Definition of additional constraints for activity models;

6. (Automatic) Test of activity models' soundness. Derivation of the

object-centered process models net. Generation of default rule-set models; foreach true do

7. (Manual) Adaptation of one of the system object-centered models;

8. (Automatic) Test of models' soundness. Change of the affected models; end

Implementation Aspects. Algorithms were developed for the generation and completion of object and activity models, and to derive simple and compound process models. Object-centered models were formalized and their soundness criteria defined. To assure the execution, advanced verification, instances migration and interoperability of the target models, a mapping to YAWL was defined. As the set of object-centered models can be considered a high-level domain-specific language to lower-level constructs provided by YAWL, syntax specification and model-to-model transformations were defined using ASF+SDF.

\section{Conclusions}

Activity-centered approaches are limited in modeling data-intensive processes. Such limitations can be translated into a set of requirements that foster the ability to process models evolve in data-intensive landscapes. Emergent objectcentered approaches do not successfully satisfy all requirements, which may be correlated with their limited practical applicability and impact. Such approaches 
provide important principles to satisfy the introduced requirements. More mature object-centered models can benefit from their mutual support.

These principles are not mutually exclusive in an event-driven solution basis centered on expressive object models. The alignment between object and activity models, although preserving the models independence, fosters an evolution of process models centered on object models adaptation. Model-to-model transformations were used to implement the target approach.

Possible lines of though for future research comprise the development of an usable graphical layer on top of the textual models, the continuously systematization and enrichment of rule-set models expressivity, the conception of an hybrid approach for heterogeneous systems where object-centered modeling plays its part, and the attachment of semantics to objects so their composition and constraints can be dynamically derived to satisfy sets of system goals.

Future publications will work on the hypothesis that expressive, sound and executable process models can be derived from object-centered models.

\section{References}

1. S. Abiteboul, L. Segoufin, and V. Vianu. Modeling and verifying active xml artifacts. IEEE Data Eng. Bull., 32(3):10-15, 2009.

2. A. Abrahams and D. Eyers. Using annotated policy documents as a user interface for process management. In $I C A S^{\prime}$ ' \%, page 64, DC, USA, 2007. IEEE CS.

3. P. Barthelmess and J. Wainer. Workflow systems: a few definitions and a few suggestions. In COCS '95, pages 138-147, New York, NY, USA, 1995. ACM.

4. K. Bhattacharya, C. Gerede, R. Hull, R. Liu, and J. Su. Towards formal analysis of artifact-centric business process models. In Alonso, Dadam, and Rosemann, editors, BPM, volume 4714 of Lecture Notes in CS, pages 288-304. Springer, 2007.

5. Ilia Bider. Choosing approach to business process modeling - practical perspective. In Journal of Conceptual Modeling, January 2005.

6. D. Cohn and R. Hull. Business artifacts: A data-centric approach to modeling business operations and processes. IEEE Data Eng. Bull., 32(3):3-9, 2009.

7. F. Corradini, A. Polzonetti, R. Pruno, and L. Forastieri. Document exchange methodology for collaborative work in e-government. In DEXA '06, pages 283287, Washington, DC, USA, 2006. IEEE Computer Society.

8. Jan L. G. Dietz. Architecture - Building strategy into design. Academic Service, The Hague, Netherlands, 2008.

9. D. Domingos, A. Rito Silva, and P. Veiga. Workflow access control from a business perspective. In ICEIS (3), pages 18-25, 2004.

10. D. Dori. Object-process methodology as a bp modelling tool. In ECIS '00, 2000.

11. C. Fritz, R. Hull, and J. Su. Automatic construction of simple artifact-based business processes. In ICDT '09, pages 225-238, New York, NY, USA, 2009. ACM.

12. A. Guabtni and F. Charoy. Multiple instantiation in a dynamic workflow environment. Advanced Information Systems Engineering, pages 175-188, 2004.

13. V. Künzle and M. Reichert. Towards object-aware process management systems: Issues, challenges, benefits. In Enterprise, BP and IS Modeling, volume 29 of Lecture Notes in BIP, pages 197-210. Springer Berlin Heidelberg, 2008. 
14. V. Künzle and M. Reichert. Integrating users in object-aware process management systems: Issues and challenges. In Rinderle-Ma, Sadiq, and Leymann, editors, BPM Workshops, volume 43 of Lecture Notes in BIP, pages 29-41. Springer, 2009.

15. Mark H. Linehan. Ontologies and rules in business models. In $E D O C W^{\prime} O \%$, pages 149-156, Washington, DC, USA, 2007. IEEE Computer Society.

16. R. Liu, K. Bhattacharya, and F. Y. Wu. Modeling business contexture and behavior using business artifacts. In J. Krogstie, A. Opdahl, and G. Sindre, editors, CAiSE, volume 4495 of Lecture Notes in CS, pages 324-339. Springer, 2007.

17. M. Merz, B. Liberman, and W. Lamersdorf. Using mobile agents to support interorganizational workflow-management. Int. Journal on Applied AI, 11(6), 1997.

18. D. Müller, M. Reichert, and J. Herbst. Data-driven modeling and coordination of large process structures. In OTM Conferences (1), pages 131-149, 2007.

19. D. Müller, M. Reichert, and J. Herbst. A new paradigm for the enactment and dynamic adaptation of data-driven process structures. In CAiSE '08, pages 48-63, Berlin, Heidelberg, 2008. Springer-Verlag.

20. P. Nandi, D. König, S. Moser, R. Hull, V. Klicnik, S. Claussen, M. Kloppmann, and J. Vergo. Introducing business entities and the business entity definition language. Technical report, IBM, 2010.

21. M. Rahaman, Y. Roudier, and A. Schaad. Document-based dynamic workflows: Towards flexible and stateful services. IEEE Congress on Services, 0:87-94, 2009.

22. H. A. Reijers, S. Limam, and W. M. P. van der Aalst. Product-based workflow design. J. Manage. Inf. Syst., 20(1):229-262, 2003.

23. W. Sadiq, K. Schulz, M. E. Orlowska, and S. Sadiq. When workflows will not deliver: The case of contradicting work practice. In Witold Abramowicz, editor, BIS '05, pages 69-84. Wydawnictwo Akademii Ekonomicznej w Poznaniu, 2005.

24. H. Schonenberg, R. Mans, N. Russell, N. Mulyar, and W. M. P. van der Aalst. Process flexibility: A survey of contemporary approaches. In J. Dietz, A. Albani, and J. Barjis, editors, CIAO! EOMAS, volume 10 of Lecture Notes in Business Information Processing, pages 16-30. Springer, 2008.

25. Hong Linh Truong and Schahram Dustdar. Integrating data for business process management. IEEE Data Eng. Bull., 32(3):48-53, 2009.

26. G. van Bussel, F. Ector, G. van der Pijl, and P. Ribbers. Building the record keeping system: Process improvement triggered by management of archival documents. In HICSS '01, volume 8, page 8060, Washington, DC, USA, 2001. IEEE CSociety.

27. W. M. P. van der Aalst, P. Barthelmess, C. Ellis, and J. Wainer. Workflow modeling using proclets. In CooplS '02, pages 198-209, London, 2000. Springer-Verlag.

28. W. M. P. van der Aalst and P. Berens. Beyond workflow management: productdriven case handling. In GROUP '01, pages 42-51, NY, USA, 2001. ACM.

29. W. M. P. van der Aalst, R. S. Mans, and N. C. Russell. Workflow support using proclets: Divide, interact, and conquer. IEEE Data Eng. Bull., 32(3):16-22, 2009.

30. W. M. P. van der Aalst and K. van Hee. Workflow Management: Models, Methods, and Systems. MIT Press, 2002.

31. W. M. P. van der Aalst, M. Weske, and D. Grünbauer. Case handling: A new paradigm for business process support. Data and Knowledge Eng., 53:2005, 2005.

32. I. Vanderfeesten, H. Reijers, and W. van der Aalst. Product based workflow support: Dynamic workflow execution. In Bellahsene and Léonard, editors, CAiSE, volume 5074 of Lecture Notes in CS, pages 571-574. Springer, 2008.

33. Mathias Weske. Business Process Management: Concepts, Languages, Architectures. Springer-Verlag New York, Inc., Secaucus, NJ, USA, 2007.

34. Michael zur Muehlen. Volume versus variance: Implications of data-intensive workflows. IEEE Data Eng. Bull., 32(3):42-47, 2009. 